\title{
LXXIII. On the constant voltaic battery
}

\author{
J.F. Daniell Esq. For. Sec. R.S.
}

To cite this article: J.F. Daniell Esq. For. Sec. R.S. (1842) LXXIII. On the constant voltaic battery, Philosophical Magazine Series 3, 21:140, 421-422, DOI: 10.1080/14786444208621601

To link to this article: http://dx.doi.org/10.1080/14786444208621601

册 Published online: 01 Jun 2009.

Submit your article to this journal $\pi$

III Article views: 3

Q View related articles $₫$ 


\section{$\left[\begin{array}{ll}421 & 1\end{array}\right]$}

\section{On the Constant Voltaic Battery. By J. F. DaNIELL,}

Esq., For. Sec. R.S., Prof. Chem. in King's College, London; in a Letter addressed to R. Phillips, Esq., F.R.S., \&c.

\section{Mx DEAR Sir,}

T T appears from Professor Grove's letter, published in the I last Number of the Philosophical Magazine, that I was under a misconception in supposing that he had derived his battery from principles announced by me; and that my memory was treacherous in suggesting that I had heard him, at a very crowded meeting of the members of the London Institution, admit (with a compliment which was impressive, but doubtless much greater than the occasion required) that it was in following up my train of reasoning that he was led to the construction of the instrument whose wonderful powers he was then about to illustrate. But waving this point of recollection, the error is certainly excusable, inasmuch as the nitric acid battery exactly resembles the constant battery in every particular except the substitution of platinum and nitric acid for copper and sulphate of copper ; and an experimentalist might, very obviously, have been led to the change by following up the principle of diminishing contrary electromotive powers and resistances to a current originating with the zinc. Professor Grove, however, states (although he "cannot at this distance of time well describe what effect my experiments had upon his mind") that he cannot acquiesoe in the assertion that he was so guided; but that the idea which immediately led to the construction of his battery is distinctly stated in the Phil. Mag. for 1839 . The experiment referred to, with two strips of gold leaf in nitric and hydrochloric acids, separated by a porous diaphragm, showing that upon contact of the two strips the gold in the hydrochloric acid was dissolved, is certainly a most beautiful one; but the origin of the force must be admitted to be at the junction of the two acids; which, when a path for its circulation is opened, react upon one another, and transfer by their polarization chlorine to one electrode, and hydrogen to the other; the former being taken up by the gold, and the latter by the nitric acid. What this has to do with the nitric acid battery, in which the two acids in contact are the nitric and sulphuric, I really cannot perceive. The origin of the force in this case has always appeared to me to be the action of the zinc upon the dilute sulphuric acid, but Professor Grove may possibly consider it to be still the contact of the two acids. He has, however, stated that he was so led to the construction of his battery, and I can have nothing more to say upon the subject. 
It is singular enough that M. E. Becquerel's claim for his father's priority in the discovery of the principles upon which my battery is constructed appears from his reply (also published in the last Number of the Phil. Mag.) to be founded principally upon a similar supposed generation of force at the contact of the two liquids.

If this be its true origin, $I$ at once allow that there is some foundation for the reclamation; but at the same time I must repeat that such an idea never occurred to me; as will be evident to those who will take the trouble to consult my consecutive papers in the Philosophical Transactions: and I must in that case be content with the somewhat mortifying reflection that I was led to a right result by wrong principles.

The matter is, however, now fairly before the scientific community, and having corrected M. Becquerel's inadvertent remark about the priority of Professor Grove's experiments, I will promise you to take up no more of your valuable space with the subject. I remain, dear Sir, very truly yours,

King's College, Nov. 2, 1842.

J. F. Daniell.

To R. Phillips, Esq., \&.c. \&c.

LXXIV. On certain Arguments adduced in the last Number of the Philosophical Magazine. By the Rev. P. Kexland, M.A., F.R.SS. L. \& E., F.C.P.S., \&o., Professor of Mathematics in the University of Edinburgh, late Fellow and Tutor of Queen's College, Cambridge.

My dear Sir,

To Richard Taylor, Esq.

THE Philosophical Magazine has this moment reached 1 me, by which I am sorry to see that a misprint, or rather a mis-transcription of my paper in the 6th volume of the Cambridge Transactions has led both $\mathrm{Mr}$. Earnshaw and $\mathrm{Mr}$. O'Brien astray. I ought to take the blame of this on myself, and do so ; your readers will find my acknowledgement of it at p. 347 of the last Number of your Journal. The three quantities which Mr. Earnshaw copies in p. 341 are not equal. I supposed the axis of $y$ to be that along which transmission takes place, and ought to have made the first and last expression equal to $n^{2}$, and the middle one to $n_{1}^{2}$; and so in my own copy it is, but I presume the correction was made with a pen. The equality of these two expressions has been employed by Mr. O'Brien to prove that I do not suppose the axis of $y$ to coincide with the direction of transmission ; and if, in applying the equations I had used these quantities as equal, the argument would have been a strong one. But on 